\title{
Artelogie
}

Recherche sur les arts, le patrimoine et la littérature de l'Amérique latine

17 | 2021

Transformaciones en Cuba contemporánea: cultura y sociedad

\section{El sujeto femenino y la anarquía en el arte cubano contemporáneo}

\section{Helga Montalván Díaz}

\section{OpenEdition}

\section{Journals}

Edición electrónica

URL: https://journals.openedition.org/artelogie/9785

DOI: 10.4000/artelogie.9785

ISSN: 2115-6395

Editor

Association ESCAL

Referencia electrónica

Helga Montalván Díaz, «El sujeto femenino y la anarquía en el arte cubano contemporáneo», Artelogie [En línea], 17 | 2021, Publicado el 27 septiembre 2021, consultado el 15 septiembre 2022. URL: http:// journals.openedition.org/artelogie/9785 ; DOI: https://doi.org/10.4000/artelogie.9785

Este documento fue generado automáticamente el 15 septiembre 2022

All rights reserved 


\title{
El sujeto femenino y la anarquía en el arte cubano contemporáneo
}

\author{
Helga Montalván Díaz
}

\section{Introducción}

1 Me sorprende la analogía, aparentemente coincidente, de la última frase de un texto dedicado a la práctica artística femenina, publicado en La Gaceta de Cuba no.1, 2004 por Suset Sánchez donde enunciaba: «Al final, en estos tiempos convulsos, a quien le interesa el género» ${ }^{1} \mathrm{y}$ un texto de corte sociológico publicado en la Revista Temas no. 37-38, del mismo año, de Stuart Hall: "Quién necesita la identidad"2.

2 El primero anuncia un hastío del síndrome del género. El segundo, su necesidad política e ideológica. Ambos abordan el género a partir de la sexualidad y las condiciones contextuales de jerarquía. Este tema en nuestro contexto, específicamente en el plano de las artes visuales, no cuenta con un cuerpo teórico sólido, aunque me temo que la obra artística, de por sí, suple el vacío dejado por los estudios. Y precisamente, por esta necesidad y el innegable trabajo de las creadoras, dudo mucho que todo esté dicho, mucho menos acabado.

3 No es menos cierto que hay artistas que han trabajado el tema sin una sobreexpuesta voluntad política, aquella que se afianza en la trasgresión de los espacios normados por la tradición cultural. Pero también hay obras en las que se ha accionado con los sentidos arbitrarios de lo impuesto hasta revertirlos. Además de quienes conocen las estrategias del llamado sistema de poder falocentrista y las utilizan, estableciendo juegos con los predios de la legitimación, llevando a niveles extremos esa diferencia adorada y temida que es la periferia y en el caso de la mujer, su doble condición de sujeto marginado. 
4 Aunque haya aún hoy artistas que esgrimen la aguja, el mantel, y los espacios más privados del cuerpo y el cotidiano, ahondando en discursos autorreferenciales, hay quienes se desprenden de estos espacios por una inmanencia ${ }^{3}$ de lo individual, no solo desde el yo, sino también desde la subjetividad. Una extensión que es más que una manta sobre el erecto masculino. Es la expansión de un universo que no se erige a partir de un polo opuesto, sino como núcleo, como ente que se universaliza y anula lo demás. No hay más reversión de la ley que obviar la ley misma.

$5 \quad \mathrm{Y}$ en este sentido vuelven las analogías.

$6 \quad$ Los espacios virtuales de la red han generado un nuevo momento también social, y las feministas no lo han obviado. Se da la posibilidad de construir identidades múltiples y esto anula la dualidad de género. También la inmanencia de esta anulación.

7 El feminismo en planos internacionales ha llegado entonces a otro status. La lucha descarnada de las Guerrillas Girls y las Judy Chicago ha evolucionado en estas condiciones a posiciones tan radicales que obvian el sentido primigenio del feminismo. Este movimiento se ha denominado Ciberfeminismo, definidas por vez primera a partir de la Documenta de Kassel en 1991 con el Manifiesto de «La Zorra Mutante» y las «100 antitesis» y representado por dos vertientes: las cyborg ${ }^{4}$ y las ciberpunk ${ }^{5}$, en las que

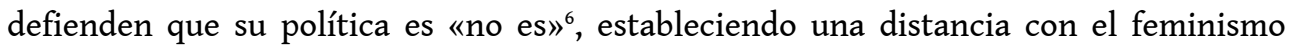
anterior.

8 Los estudios que sobre este feminismo desarrolla Rossi Braidotti ${ }^{7}$ señalan algunos sentidos que determinan la práctica de estas artistas: La política de la parodia, en la que se esgrime la mimesis como fuente de poder político y supone un enfoque deconstructivista de la feminidad, actuando como si la Mujer fuese todavía su sitio; el poder de la ironía, con el objetivo de desactivar una retórica vehemente. Además de las posturas que instauran a la madre como antimodelo del nuevo feminismo, una posición que deviene radical frente al feminismo anterior.

9 A pesar de estas acciones de las ciberfeministas, la tecnología sigue estando en manos del poder, de las estructuras de dominación institucionales. En definitiva: ¿A quién le sirve la tecnología de la información?

10 Aquí. No somos cyborg ni drásticamente punk. Hemos tenido algo en pequeñas dosis en la rebeldía del grupo de artistas de 609, algo de la sutil irreverencia de Tatiana Mesa, pero nunca como las posiciones radicales del grupo de las Judy Chicago ni de las Guerrillas Girls. No en sentido de instituir el feminismo. Me refiero a una toma de opinión política desde lo personal.

11 Tenemos una formación diferente.

12 En nuestro contexto artístico las artistas han trabajado la ritualidad a partir de la influencia paradigmática de Ana Mendietta con el sentido que conlleva tal implicación desde la posición espiritual y social de la mujer, redimensionando el tema a niveles conceptuales, y que ha dado sus frutos en el hacer de Tania Brugueras, Martha M. Pérez; Maria Magdalena Campos; cada una desde su propio discurso y asociado a los diferentes resortes de sentido que afianzaban también otras experiencias.

13 Tenemos a Elsa Mora, de objetos punzantes, casi sadomasoquistas. A Aimeé García y sus tejidos y agujas de dolor, de tiempo, su mantel de cobre inamovible. A Litzie, más mínimal y también doliente. Pero además a Belkis Ayón, que sí se inmiscuye en el espacio más controversial y cerrado del poder, reconstruyendo, redefiniendo, y aún 
más, insertándose en el devenir de una otredad maldecida de ser La Mujer, reivindicando su propio papel en la historia de la raza, de la cultura, de sí misma.

Las artistas se han afianzado a su rol y a partir de él han reestructurado, no solo desde los modelos de imitación fetichista, y sí de su simulación reordenando los sistemas de una historia en la que en apariencia han devenido partícipes y se han anunciado como sujeto.

15 Concuerdo con Suset Sánchez en que ha habido un cambio donde lo lúdico ha influido, pero tampoco ha sido lo que lo ha determinado. El juego y el cinismo vienen dando frutos, más que tumbos, desde los tempranos años noventa y sus metáforas. Pienso que los caminos que nos han llevado a lo que aquí se propone como anarquía en la práctica artística femenina viene dado por razones más concretas.

Nosotros intuimos el espacio de libertad. Y eso no tiene que ver con la intuición femenina. Nuestros canales de acceso son otros, radicalmente alternos. Tenemos estructuras de educación que propician el conocimiento, la posibilidad, incluso modos de aprender a trabajar con todos los programas del PC y conocemos la tecnología digital. También representación política y massmedia mediados. Además de otros modos. No solo los institucionales sino los underground. Los cables piratas, los CD, los DVD, los bancos de películas, revistas extranjeras y los textos que nos descargan y nos dejan los amigos de Internet.

Tenemos el fantasma de la tecnología. Su instrumental material, solo que el módem no funciona para todos. Pero contamos con el subterfugio. Hemos construido las metáforas, las parábolas, las elipses. Sabemos que el espacio de libertad existe. Tenemos que simularlo.

18 Lo que ha tenido lugar tiene que ver con un cambio en el efecto de perspectiva. Ya no es únicamente necesaria la relación dual para erigirse. Se ha revertido la norma en el hecho artístico, y a pesar de lo factual de la temporalidad espacial y vivencial del cotidiano, podemos inventar el espacio de la inmanencia. Una apolítica que se vuelve anárquica frente al supuesto poder instaurado desde las bases de la memoria de nuestra cultura. Se ha formulado un modelo de simulación de poder, subvirtiendo su regla a favor de una transfiguración de la realidad que redefine locaciones a las que no les interesa instaurarse, no más que sí mismas.

19 Para esto nada mejor que potenciar la propia experiencia desde lo subjetivo, llevándola a los predios de lo espectacular: los prometedores efectos del simulacro.

Lázara Castellanos, en su artículo "Discursos de Mujeres, una reflexión dentro de las artes visuales cubanas" ${ }^{8}$ señalaba: «Cuando las mujeres artistas como problematicidad de lo contemporáneo investigan, no sólo [lo hacen] en la tradición plástica históricamente heredada cuya característica falocéntrica es innegable sino dentro de sí mismas. Su indagación avanza desde las márgenes hacia el centro, desde sus diferencias sexuales: sus senos, su vagina, el útero, el clítoris, las localizaciones de su placer, su vergüenza y su dolor, e insiste en el desentrañamiento de una entidad, un "yo" que es parte inalienable de un "nosotros". Sus obras establecen un diálogo difícil con un espectador escindido entre su formación por una cultura machista, la causística relación con estas obras y sus propuestas completamente tendenciosas», afianzando las zonas corporales como elemento común, marcado por el sentido del drama y el silencio, vistos en obras también de Sandra Ceballos, Sandra Ramos, Tania Brugueras. 
21 Adelaida de Juan, por su parte, da por sentado el hecho de que: «Las situaciones femeninas son vistas con ojo crítico, con una mezcla de conciencia, denuncia y aceptación interiorizada» ${ }^{9}$ bajo la estrategia discursiva, también señalada por la autora, de la ausencia/presencia. Lo que me hace volver a señalar el hecho de que en apariencia nuestra posición política es activa en el marco social y político, no así en el imaginario colectivo que emana de la memoria cultural. Estas reflexiones van direccionando lo que puede entonces definirse como una identidad genérica, vista en la práctica artística femenina, que va conformando los enclaves de su determinación.

Suset Sánchez en «El sabor de la galleta olvidada sobre la mesa» ${ }^{10}$ imbricaba además este hacer desde el pretexto de la historia y los emplazamientos propiciados por la obra de artistas como Aimeé García y Gertrudis Rivalta. También se acercaba en este artículo a la producción de artistas emergentes, señalando el juego y «el chiste» como condición de estas propuestas, lo que ha mi modo de ver, la crítica esgrimía como especie de vaciamiento y distanciamiento de la postura política -y también ideológica- de lo femenino.

Pero dudo de tal distanciamiento. Creo más en el desplazamiento y su desafío. Los discursos anteriormente expuestos conviven hoy con ese otro fenómeno devenido anarquía, condicionado y generado por el contexto, y que se relaciona con la apropiación de una atemporalidad, reordenada en los espacios de la ironía, la parodia y la simulación, tomando posiciones completamente apolíticas, generando una autoría proclamada por un sujeto no determinado por su contrario y sí expandido en sí mismo. Ya no hay oposición. No hay necesidad de afianzarse a través del otro.

Podríamos señalar tres posturas devenidas de una resignificación de las propuestas de Braidotti, ajustándolas a nuestro contexto mediante la diferenciación que establecen nuestras propias condiciones tecnológicas y sociales, reformuladas a partir de una situación particular propiciada desde la historia política de la mujer cubana y sus modos de comportamiento e inserción en las relaciones que establece la jerarquía.

Una sería a partir de las apariencias del modelo de imitación de la norma, ese otro silenciado, venido de la memoria cultural.

La segunda estaría dada por la generación de un espacio atemporal, virtual, inmaterial, irreal, reformulado a partir de la matriz del simulacro y la incidencia en nuestro medio de las experiencias vivenciales anunciadas por lo tecnológico y la presencia de los medios.

Una tercera señalada por su respuesta al pensamiento anterior, al ideal de La Mujer, que redefine los modelos de normatividad de «este» femenino, a partir de su reconstrucción, asociado también al fetiche y el rol de la mujer en la práctica social.

He de señalar que en nuestro contexto, la mediación de lo artístico atenúa la crítica desde lo político en niveles macro sociales, sin embargo señalan otra ideología que se anuncia subversiva, no a través del cuestionamiento sino mediante su instauración. Y esto sí es irreverencia.

Esta posición es archiconocida en obras de Rocío García, como la exposición presentada en Galería Habana: El domador y otros cuentos. No obstante, me interesa trabajar en particular sus series Geishas, de 1995 y Haikus, del 2004.

30 En Geishas hay significaciones que refieren a la mujer en el espacio simbólico que le ha sido prefijado, solo que hay significantes que generan una suerte de ambigüedad, y un travestismo que como superficie genera el sentido de la máscara, aquí doble. Los 
personajes de García simulan participar de este espacio determinado por las jerarquías, pero en su ofrecimiento, existe una promesa de trasgresión desde el canon de la sexualidad. Se vuelve, de por sí, una promesa de lucha a pesar de erigirse sobre los resortes asociados a la idea de lo erótico, como suponen el mito de sus personajes. Mito anulado en el enfrentamiento de su condición de mujer y sus connotaciones culturales. Ya no es sólo el desafío al dominador, a quien espera con las armas que él mismo ha construido, sino que se reta a sí misma, a su propia identidad caduca y harta de su rol.

De ahí se desprenden dos de las posturas que antes mencionaba. Trabajando con el modelo de imitación de la norma, los personajes de Rocío García se anuncian como entes subversivos del espacio prefijado, en el cual el hombre hace presencia por los objetos forjados en su historia y apropiados por la artista, instrumentos factuales de sometimiento. Socava entonces el rol masculino y reubica de modo radical el femenino. Así mismo, va configurando las direcciones del cuestionamiento de la connotación de su identidad y los modos en que esta se ha afianzado.

Haikus promete otros sentidos. Aquí se trabaja también a partir de lo que hemos definido como modelo de imitación, retomando el mito de Mujer-Naturaleza. Los haikus son formas poéticas con una estructura depurada y mínimal, suficiente, elemento formal que la artista revierte en la imagen plástica.

La Mujer se hace única protagonista del espacio y de los órdenes que rigen, determinando el poder en acciones de traspaso. Subvierte entonces el sentido de lo instaurado a favor de un espacio que expande y del cual se hace protagonista única. Reconstruye con esto el sentido de la memoria histórica insertándose en su centro, su génesis, no como "diosa" cyborg o punk, sino como ente cognitivo, portador de los sistemas de reordenamiento. Ella es quien dirige los eventos.

34 Además resulta inquietante el porqué la artista toma signos de una cultura no por lejana desconocida, y que influye en la nuestra con todo el arsenal de lo exótico y la atrayente ritualidad de las relaciones y los sistemas que ha establecido. Sus ejercicios calan en el imaginario colectivo como significante portador de no pocas estrategias donde la seducción resulta determinante. La artista deconstruye estos sentidos mediante la simulación de una serie de acciones donde la apariencia establece analogías que resultan invertidas a través del juego anárquico con la tradición, un modo de inmiscuirse en la historia para anular y disgregar sus sistemas de instauración, estableciendo entonces su propio espacio de autonomía. No hay dolor. Nada de drama. Es la acción que genera el núcleo, la apariencia y simulación de la centralidad. La construcción de una perspectiva otra, a partir de los canales que la historia le ha conferido. Sería entonces el sentido de la mimesis el medio por el cual hace suya la fuente de poder.

35 Bajo este signo se desarrolla también la obra actual de Sheyla Castellanos, artista conocida por su serie Novias, del 2000 y su consecutiva expo Impúdicas escenas del límite, donde la rebeldía asomaba a través de una marcada verticalidad y una sobreexpuesta escenificación de ciertas constantes asociadas al discurso de género. Pero su hacer ha optado por otros derroteros.

Si Rocío García se apropiaba de los sistemas instaurados por la historia del poder falocentrista para simularlos y ponerlos a los pies de lo femenino, mediante una feminización de sus estructuras, Sheyla Castellanos propicia el arsenal de los modos que le han sido instaurados en la mirada de la historia del arte a la mujer, para 
desplazarlos al hombre, revirtiendo también su acción. Ha feminizado la mirada hacia lo masculino, por extensión.

Castellanos trabaja con los referentes historicistas, asociados particularmente a la pintura de género como aprehensión de sus espacios conferidos por la nombrada jerarquía, con los modos del neoclásico y ciertos elementos referentes al novau, creando ambientes eclécticos donde lo ambiguo rige también como promesa de sentido. Sus personajes se muestran en completa complacencia, sabiéndose mirados y en esta pose no hay nada de enfrentamiento y sí de disfrute. Aquí estamos también ante el modelo de imitación. Todo simulado.

En El ángel de Alied, la artista traspola el rol femenino al masculino. Se apropia entonces de las investiduras que el arte le ha conferido al sujeto mujer para reafirmarlos en él. Su postura de reposo -como David relegara a la historia su Madame Récamier-los adornos de lo femenino le son impuestos propiciándole un rol aquí asumido y aprehendido, infiriendo la subversión de la ideología del poder convencional, «occidentaloide», afianzado en la horizontalidad y los aditamentos que suponen la construcción del confort del artificio; descentrando los sistemas de la construcción histórica.

Es entonces una estrategia sutil y encantada, aparentemente banal y vacía, que se escabulle entre las normativas sociales mediante la simulación de su aceptación. No pueden dejar de seducirte. $\mathrm{Y}$ es entonces donde erige su espacio de anulación, su muerte.

40 Humo al vacío confirma la idea anterior. El hombre es mostrado en el canon masculino implícito de nuestra cultura en el acto de fumar. Aquí descentrado en esta aparente levedad provocada por el placer que supone el acto. Sheyla Castellanos vuelve a utilizar las estrategias que suponen conferirle su máscara -la de ella. El personaje de esta obra es específicamente contemporáneo, mas el ambiente en que se inserta es decimonónico. A pesar de su imagen y eventuales atuendos, el todo es supeditado al espacio de poder femenino, símbolo también de su sexualidad que es el óvalo, llevado a una posición de horizontalidad. La mirada es oblicua, distante, sugiriendo una temporalidad que clama la seducción desde la filiación del secreto que promete. Ella le ha impuesto su propio secreto, su estigma.

41 Con los autorretratos, la artista opta por la lateralidad, cuando no el total desinterés. Construye un universo paralelo radicalmente alterno, donde acciona sobre polos de jerarquía genérica, con las armas que la historia del arte ha conferido como enfoque sobre la mujer. Extiende su signo a favor también de la feminización, creándole el artificio diluido en los sistemas jerarquizantes a través del elemento de lo subjetivo. Su doble juego connota un cinismo subversivo al erigirse aparentemente sobre las bases de una ideología heredada por el sujeto femenino como norma.

Este otro espacio, sugerentemente alterno y que destaca su inmanencia, su paralelismo a lo real, es trabajo además de Analía Amaya y Glenda León, quienes en sus propias construcciones no dejan de seducir desde una subjetividad marcada por su aparente inmaterialidad. En el caso de Analía Amaya, se construyen no-cuerpos, no-espacios. Su interés en proyectar imágenes dota a su obra de una atemporalidad inquietante, entendida en el ejercicio más pleno del simulacro, afianzándose entonces a la segunda propuesta.

43 Lo que la artista construye es el artificio, la simulación de lo subjetivo. Su alteridad se inserta entonces en el espacio social que interviene, y es en este donde genera un 
rompimiento en los rituales de la cotidianidad. Lo que más impacta en su obra es precisamente ese logro mediante lo tecnológico, incluso lo artesanal, no específicamente lo digital. Crea locaciones en las que la apariencia de una inmanencia virtual confiere identidades predeterminadas al espacio intervenido, ya sea urbano o galerístico, accionando una sublimación que también emplaza una atemporalidad marcada en ocasiones por el tempo del mito, a través de la potenciación de lo intrascendente a través de la construcción del efecto.

Crea entonces el espacio de la subjetividad femenina, la hace presencia a través de la observación conciente del medio, objetivando lo intrascendente, como sucede en la obra Diez del día. En su instalación Después del diluvio, hace factible también estas estrategias proporcionándole el tiempo de la nostalgia señalando coordenadas marcadamente existenciales, aquí vistas en la gota -de lluvia o la lágrima- y el constante caer. Sus obras potencian sentidos inmersos en la subjetividad individual, compulsados al espacio cotidiano mediante un efecto espectacular que desata los resortes de la experiencia común y la colectiviza a favor de lo trascendente.

Con Land-scapes, exposición del 2004, su imagen proyectada en la escalera activa todos los resortes que la seducción supone, trabajando en la absorción del reflejo mediante lo inmaterial, el no-cuerpo. Síndrome agonístico. Total desafío de la seducción que anula el deseo. Va más allá de la subversión del eterno femenino, es su potenciación en una extensión radical y alucinante de su propio poder.

Es entonces el simulacro su estrategia, la construcción de un artificio desde una subjetividad que invierte no solo el espacio real, sino también todas las matrices que la norma ha impuesto. La imposibilidad de acceso del poder convencional. La imposibilidad de concretar el deseo. El eterno juego de la seducción. Una distorsión subversiva de la perspectiva de la realidad y sus sistemas, la susceptible arbitrariedad de lo real.

47 En el caso de Glenda León, la subjetividad de lo femenino se inserta desde el placer de sus acciones inclusivistas. Sus ambientes recrean cierto sentido de lo inmaterial, también. El efecto de irrealidad es puesto aquí a favor de una alteridad que significa determinados elementos devenidos de lo existencial y de su propia experiencia.

Lo lúdicro hace presencia desde una perspectiva que socava los espacios y medios de generación del poder, intervenidos a favor de un enmascaramiento que feminiza los objetos instrumentales por los cuales se implanta la jerarquía convencional. Su ejercicio es el de incidir en los espacios que la sociedad le ha distanciado, a través de un sentido mínimal que construye el efecto del goce y lo intrascendente. Su postura, deudora de los readymades dadaístas, propone asociaciones que insertan el signo mujer en la dinámica artística provocando un desplazamiento del sistema. Con esto afianza una reconstrucción o un nuevo enfoque de su identidad genérica, extendida en la reescritura que implica su acción inserta en las relaciones predeterminadas del campo de lo artístico.

Otros sentidos son anunciados en la obra de Gertrudis Rivalta, quien exige la determinación de coordenadas particulares. Su hacer se inscribe en los discursos sobre lo social y la emergencia de su memoria actuante e histórica, imbricada también a experiencias personales. Su voluntad es la revisión y constatación de una ideología particular, activo como lo es su hacer desde las posiciones de género y raza. 
50 En sus últimas obras, la artista ha trabajado la construcción de la figura de la mujer en nuestro contexto a partir de la memoria visual y social, desde una aparente superficialidad que indaga y cuestiona los eventos que la han definido; recreando incluso los espacios cotidianos a los que ha sido supeditada, pero compulsando en estos los resortes de sentido que le interesan. Estaríamos aquí frente a una posición militante, que parte del modelo de imitación de la tradición para subvertir, parodiar e ironizar sus espacios, con una voluntad radical que la inscribiría en la tercera propuesta. Gertrudis esgrime el cinismo como ejercicio reconstructivo y desacralizante.

51 Desde Las dos Fridas y los mosquiteros hasta La novia del Kremlin, la serie de las tereskovas y la serie de las pompas de jabón, Gertrudis ha pasado de la agonía de lo existencial a los eventos más factuales del cotidiano. Su poder de ironizar desde las connotaciones de la superficie no tiene límites. A través de lo absurdo deconstruye una ideología particular y su propio fetichismo, desde un posesionamiento del espacio de autonomía de la mujer.

Como Rocío García, Gertrudis Rivalta, desde otro enfoque, subvierte su espacio no solo social sino el que la define como género, desajustando la retórica de sus valores prestablecidos y reescribiendo sus propias relaciones con el entorno social y existencial, como pasa en La novia del Kremlin. Esta obra impacta por el efecto de su perspectiva, la cual también atañe al continuo de los ritos instaurados en la memoria social como tradición. Muestra entonces una hija rebelde que desafía al artificio construido sobre sí, y a su pesar, por las instancias emanadas de las relaciones de los sistemas instaurados. Factuales en cuanto contrapone dos ideologías convergentes en la conciencia social, denotando el elemento de la máscara hilvanado en el sentido de la superficialidad del fetiche y no su absorción. Un desafío que revierte su perspectiva en el espacio femenino, hacia sí mismo, centralizando el poder de su postura.

53 Con sus tereskovas y las pompas, la artista enmascara, a través una ironía donde pulsa lo absurdo como cuestionamiento de una idea determinada por condiciones contextuales, apropiadas por una supuesta naturaleza devenida en glamour y que subvierte las utopías del rol social marcado únicamente por el deseo.

Ridiculiza a estas mujeres aparentemente irreverentes y dueñas de su momento. Contrapone entonces dos sentidos determinantes en la identidad genérica de «nuestra» mujer: la persistencia de los modelos fetichistas venidos de la formación Occidental, y los atributos que sugieren la aprehensión superficial de una cultura completamente ajena. De las anomalías que supone la confrontación de estos elementos, Rivalta reconstruye el mito del papel activo y reformador de la mujer como ente portador de una identidad política y social, socavando entonces los argumentos instaurados.

La Hija cuestiona entonces el rol de La Madre mediante una postura desacralizadora y abiertamente radical, descentrando las bases que la instauraron.

Las pompas señalan el evento cínico a partir de la imposibilidad de la utopía. Gertrudis Rivalta supedita a la Mujer a un espacio que «a pesar de» no ha trasgredido, solidificando y haciendo de las ansias y el deseo, el sometimiento. Sus pompas se vuelven pisapapeles que se someten a la imposibilidad, denotando un hastío de la sujeción al espacio de jerarquía asumido por esta «ella» ya caduca. Invierte la imagen de poder que la mujer se adjudica a sí misma y la enfrenta al límite de sus presupuestos y los eventos que han propiciado. Cuestiona los modos en que ha instaurado su rol desde la misma locación genérica, mediando una reconstrucción de la ideología de lo 
femenino a partir su fuente de generación, cuestionando y parodiando, enunciando la necesidad de otras estrategias.

Se asumen entonces posiciones en las que la simulación, la parodia, la ironía y el cinismo son las bases de una postura deconstructiva de los roles asumidos por la práctica artística, anunciando otras posiciones que calan en una identidad genérica reformulada en los nuevos espacios propiciados por el entorno sociocultural, determinado por lo tecnológico, aportando otros caminos en el discurso artístico.

Por supuesto el juego no está exento de estas prácticas, accionado mediante las estrategias que la simulación asigna para desde la normatividad impuesta, establecer una perspectiva doblemente alterna que invierte sus estrategias de poder, a partir de locaciones análogas. La anarquía rige de forma autónoma mediante una feminización y subjetivación de los modos de emplazamiento de los sistemas de jerarquía. Es el desplazamiento de sus ya instituidos caminos, descentralizando los ejes que los construyen.

59 Es necesario señalar que este sentido ha ido haciendo presencia y convive con otros modos presentes en el devenir histórico del arte cubano. El hacer femenino es amplio y va desde el lirismo y la poética a discursos más conceptuales, con particulares niveles intelectivos, pues nuestro espacio es en esencia moderno y sus especificidades son otras.

De todos modos esta anarquía va encauzando otros terrenos fértiles que continúan proponiendo particularidades de la experiencia de la mujer, en una posición donde no son el dolor y los dramas de la sexualidad lo que definen los resortes teóricos del discurso, sino una subjetividad más centrada y expandida a partir de sí; donde «la otra» no se instaura desde el drama de lo excluido sino que ha creado zonas alternas de generación de sentido, provocando un sujeto que no se afilia a las condicionantes heredadas que enmascaran sus estrategias de reversión de lo normativo, creando zonas de desplazamientos donde aboga su subjetividad y se instaura por sí misma.

61 Si Adelaida de Juan apuntaba en su artículo que la ausencia/presencia ${ }^{11}$ ha sido uno de los modos en que la mujer artista ha creado la obra, un efecto de perspectiva devenido en poder político ha sido la estrategia utilizada para establecer su feminización mediante una hiperpresencia, que establece analogías con la noción de "más cuerpo» ${ }^{12}$ apuntada por Ana M. Collazo. Ha expandido su accionar en locaciones donde reescribe y reordena una historia obviada y cuestionada, revolucionada de modo radical por las más recientes propuestas, definida no ya en la diferencia sino en la absorción de su ser.

Creo, en tanto, que estas artistas definen una ideología de identidad que va reajustando sus canales conceptuales no determinados por la «documentación» del drama y/o la violencia, o la exaltación intimista de la vocación de ser ninfas o diosas, sino por un conocer mucho más conciente de su propia naturaleza y su capacidad de subversión. La mujer artista ha obviado las jerarquías. Ella misma construye su propia norma mediante la reversión de la ley que la cultura dominante impone. ${ }^{1}$ 


\section{NOTAS}

1. Texto aparecido en la revista La Gaceta de Cuba, UNEAC. Ciudad de la Habana, Cuba, 2006.

\section{NOTAS FINALES}

1. Suset Sánchez, El sabor de la galleta olvidada sobre la mesa, en Rev. La Gaceta de Cuba, no.1, 2004.

2. En este texto, Stuart Hall hace un llamado sobre la necesidad de afianzarnos en nuestras identidades étnicas y genéricas por la postura política e ideológica que supone la defensa de nuestras particularidades.

3. Cuando hablo de la inmanencia, me refiero a ese espíritu o aura que también tiene efectos en la red y en el amplio espectro de posibilidades que esta promete en la construcción de identidades múltiples.

4. Vertiente de las ciberfeministas, se considera un ícono de la diosa transformado en un ciborg, la perfecta unión entre tecnología e individuo, brillante, asexuado y enteramente funcional.

5. De las ciberfeministas, las punk son la posición más rebelde, más agresiva, más irónica. Sus presupuestos y declaraciones se vuelven contra la madre y su posición social como educadora, determinada por el rompimiento con el feminismo anterior.

6. Las 100 antitésis ciberfeministas son planteamientos francamente anárquicos donde se definen como: cyberfeminism is not ...

1. cyberfeminism is not a fragrance

2. cyberfeminism is not a fashion statement

3. sajbrfeminizm nije usamljen

4. cyberfeminism is not ideology...

Y se reconocen como activistas: El ciberfeminismo es una cooperación [para la liberación de la mujer] entre mujer, máquina y nuevas tecnologías.

7. Rosi Braidotti realiza un análisis crítico de las posiciones del feminismo y las alternativas que ofrece lo imaginativo por la necesidad de instaurar nuevos modos de instituirse de acuerdo a las nuevas condiciones, estudiando entonces las estrategias mediante las cuales algunas artistas se insertan en la dinámica visual de las artes contemporáneas a partir de la política de su posición. En Un ciberfeminismo diferente; estudiosonline. http://www.rebelion.org

8. Lázara Castellanos, «Discursos de las mujeres en el arte cubano Actual: una reflexión dentro de las artes Visuales Cubanas», en Rev. Arte Cubano, no.2, 1998. Consejo Nacional de las Artes Plásticas.

9. Adelaida de Juan, Ausencia quiere decir olvido, en Rev. Temas no.14, abril-junio, 1998.

10. Suset Sánchez: Ob. Cit.

11. Adelaida de Juan: Ob. Cit.

12. Ana María Collazo define las transfiguraciones del cuerpo asexuado que defienden las ciberfeministas como la generación de más cuerpo, más allá del cuerpo real, el cuerpo virtual. En 
«Tecnología y construcción de la subjetividad: la femenización de la representación ciborg», http://w3art.es/estudios.

\section{RESÚMENES}

Cierta anarquía va encauzando terrenos fértiles que continúan proponiendo particularidades de la experiencia de la mujer, en una posición donde no son el dolor y los dramas de la sexualidad lo que definen los resortes teóricos del discurso, sino una subjetividad más centrada y expandida a partir de sí; donde «la otra» no se instaura desde el drama de lo excluido sino que ha creado zonas alternas de generación de sentido, provocando un sujeto que no se afilia a las condicionantes heredadas que enmascaran sus estrategias de reversión de lo normativo, creando zonas de desplazamientos donde aboga su subjetividad y se instaura por sí misma.

\section{ÍNDICE}

Palabras claves: Arte Cubano Contemporáneo, Feminismo, ciberfeministas

\section{AUTOR}

\section{HELGA MONTALVÁN DÍAZ}

Directora ensayista y crítica de arte Líneas de Investigación: Arte Cubano Contemporáneo, annodnarak@gmail.com 